\title{
8 El estudio de las narrativas: de la literatura a las ciencias sociales
}

Es solo en los últimos cincuenta años que el concepto de narrativa se ha convertido en objeto de investigación autónomo. Según explica Ryan (2005, p. 344), desde Aristóteles y hasta antes de los narratólogos estructuralistas, los críticos y filósofos que se habían abocado a la teoría literaria no se ocupaban de narrativa propiamente dicha sino de los diversos géneros literarios. No fue hasta los años sesenta que el estudio de las narrativas dejó de ser una cuestión puramente del ámbito literario: "It was the legacy of French structuralism, more particularly of Roland Barthes and Claude Bremond, to have emancipated narrative from literature and from fiction, and to have recognised it as a semiotic phenomenon that transcends disciplines and media” (Ryan 2005, p. 344). A partir de entonces y gracias al posterior impulso del llamado giro narrativo dentro de las ciencias sociales, las narrativas han sido centro de estudio de diversas disciplinas como la psicología, la lingüística, la educación, el derecho, la investigación en el área de salud, la teología y las ciencias cognitivas, por mencionar algunas. Su análisis se ha hecho desde múltiples perspectivas y a través de metodologías diversas que han aportado definiciones heterogéneas, muchas veces conflictivas.

A continuación, ofrecemos una panorámica de los enfoques y modelos teóricos que han contribuido de forma decisiva a que el estudio de las narrativas se convirtiera en una disciplina teórica y con metodologías propias en el campo de las ciencias sociales.

\subsection{La narrativa como un tipo de texto}

En su libro Analysing Narrative (2012), De Fina y Georgakopoulou proponen que los distintos enfoques que han tratado las narrativas se pueden clasificar de acuerdo a la manera en que estos las conciben. Distinguen entre la visión de la narrativa como un tipo de texto y la concepción de ella como un modo, epistemología y método.

De acuerdo con las autoras (2012, p. 2), concebir la narrativa como un tipo de texto implica considerarla como una actividad bien estructurada con un principio, un desarrollo y un final, construida a partir de unidades susceptibles de análisis. Asimismo, esta visión acepta la existencia de propiedades textuales universales que existen independientemente del contexto. Algunos de los objetivos planteados dentro de estos enfoques son los de revelar estas unidades mínimas, 
conocer la manera en que se adquiere la habilidad para contar historias y entender los procesos que permiten el entendimiento y producción de narrativas.

Uno de los enfoques más importantes dentro de esta tradición es la narratología, término acuñado por Tzvetan Todorov (1969, p. 10). La narratología se desarrolló en los años 60 y 70 del siglo XX durante el periodo de auge del estructuralismo. Investigadores como Roland Barthes (1977), Tzvetan Todorov (1969), Gérard Genette (1980), Gerald Prince (1987), Jonathan Culler (1980) y Seymour Chatman (1990) se basaron en esta teoría lingüística para definir los elementos comunes a todas las narrativas en términos de reglas formales. En efecto, debido a que el estructuralismo lingüístico fue el modelo sobre el que se erigió esta teoría, los narratólogos consideraron que las narrativas estaban sustentadas en un sistema semiótico común cuyos constituyentes y principios combinatorios eran el objeto de análisis (Herman 2005, p. 571). Además, expandieron los límites de investigación al considerar que la narrativa no era propia del ámbito literario. En su "Introduction to the Structural Analysis of Narratives” Barthes (1977, p. 79) sostiene que:

Narrative is first and foremost a prodigious variety of genres, themselves distributed amongst different substances [. . .]. Able to be carried by articulated language, spoken or written, fixed or moving images, gestures, and the ordered mixture of all these substances; narrative is present in myth, legend, fable, tale, novella, epic, history, tragedy, drama, comedy, mime, painting (think of Carpaccio's Saint Ursula), stained glass windows, cinema, comics, news item, conversation. Moreover, under these almost infinity diversity of forms, narrative is present in every age, in every place, in every society; it begins with the very history of mankind and there nowhere is nor has been a people without narrative.

Esta infinita variedad de narrativas, según Barthes (1977, p. 80), no podría ser analizada si no tuvieran una estructura común. Así pues, encuentra en el estructuralismo (1977, p. 82) el modelo de análisis adecuado para poder describir la infinitud de narrativas y propone que la narratología tiene el mismo objeto de análisis que la teoría saussureana, es decir, el sistema (la langue) a partir del cual se genera la multiplicidad de narrativas (la parole) y cuya estructura definirá lo que es narrativa de lo que no lo es (1977, p. 80).

La narratología ha representado el primer intento por sistematizar el estudio de la narrativa. A pesar de que esta teoría se ha abocado al estudio de textos literarios, ha tenido mucha influencia en los estudios sobre las narrativas dentro del campo de la lingüística. Sin embargo, su utilización ha presentado varios problemas. Por ejemplo, Herman y Vervaerk señalan que las categorías de análisis no son funcionales para todo tipo de narrativas por lo que "[i]n many cases the structuralist is forced to acknowledge that concrete stories always upset the theoretical demarcations” (2005, p. 100). Otra de las polémicas se centra en la 
ambigüedad de las categorías de análisis. A este respecto, De Fina y Georgakopoulou (2012, p. 4) apuntan la problemática que ha implicado la definición de historia (o narrativa, como sinónimo) para los narratólogos, quienes no siempre concuerdan: para Chatman (1990, p. 9), por ejemplo, es esencial la noción temporal, esto es, "what makes Narrative unique among the text-types is its “chrono-logic", its doubly temporal logic”. Prince, en cambio (2003, p. 53), enfatiza el elemento causal y propone que una historia mínima implica un estado inicial, un evento o acción y un resultado causado por el evento. A su vez, Herman y Vervaerk (2005, p. 13) sostienen que la noción de narrativa no debe restringirse a la sucesión de eventos conectados temporal y causalmente, sino que esta conexión puede ser también metafórica, metonímica o temática. En este sentido, afirman que una oración como "It was raining hard, in the streets as well as in his heart” es una historia mínima, ya que existe una relación entre los eventos que no es de tipo temporal ni causal sino metafórica (Herman y Vervaerk (2005, p. 14).

Otro grupo de enfoques que abordan el análisis de la narrativa como un tipo de texto son las story grammars desarrolladas por estudiosos de la psicología cognitiva y la inteligencia artificial (Rumelhart 1975, 1977; Thorndyke 1977; Mandler \& Johnson 1977; Stein \& Glenn 1979), cuyo interés fue el de descubrir los constituyentes de las narrativas y sus reglas de combinación. Para estos enfoques, la estructura interna de las narrativas sigue normas similares a las reglas gramaticales de una lengua y los elementos básicos y sus reglas combinatorias constituyen un esquema específico. Dicho esquema es internalizado y usado durante la comprensión y memorización de historias. Es decir, las personas son capaces de comprender y codificar la información de una narrativa en la medida en que pueden identificarla como ejemplo de un esquema organizacional general previamente aprendido (Thorndyke 1977, p. 79).

Otra teoría que sigue la línea cognitiva y trata de explicar el proceso de comprensión textual es la teoría de los modelos mentales de van Dijk y Kintsch (1983). Esta teoría propone que la comprensión no se realiza a partir de la integración de la información textual dentro de esquemas previamente establecidos como sostenían las story grammars-, sino a partir de la creación de modelos cognitivos que representan mentalmente la situación narrada (o vista), y que emergen sobre la marcha (on line), conforme se va recibiendo el input. Esta teoría sostiene que el oyente/espectador construye una representación mental del evento a partir de informaciones adquiridas como creencias, opiniones, actitudes, metas, etc. En este sentido, el proceso de comprensión es estratégico, ya que se combina información externa con información interna para completar la representación mental del evento y lograr la comprensión del discurso (van Dijk \& Kintsch 1983, pp. 5-6). 
El interés por el contexto que demuestra la teoría de los modelos mentales se observa en la atención que pone en el papel del receptor, sus conocimientos y creencias, así como en el contexto situacional y en la interacción entre el receptor y el emisor (sus expectativas, motivaciones e intenciones) para la interpretación del texto. Para van Dijk y Kintsch, el procesamiento del discurso no es solamente un evento cognitivo, sino también un evento social, ya que cualquier tipo de discurso, incluyendo las narrativas, son producidas por hablantes y receptadas por oyentes en situaciones específicas y dentro de determinados contextos socioculturales. En el proceso de comprensión textual el receptor construye una representación mental del texto, pero también del contexto social. Pero además de estas representaciones, al escuchar/leer un texto, el receptor construye una representación de las posibles intenciones del emisor. Así pues, los autores sostienen que el proceso de comprensión tiene una dimensión interaccional, ya que la representación mental del discurso depende tanto de las suposiciones que el oyente hace sobre las intenciones y motivaciones del hablante como de sus propios objetivos y motivaciones al escuchar el discurso (van Dijk \& Kintsch 1983, pp. 6-7).

Más recientemente se ha reconocido que la designación de un texto dentro de la categoría de narrativa no depende únicamente de sus propiedades estructurales, sino también del involucramiento emocional del receptor causado por las dificultades que la trama presenta. Este interés dedicado al rol del lector/receptor y sus conocimientos y creencias en la interpretación textual se puede observar en la narratología posclásica (Ryan 1991; Werth 1999; Herman 2002). Las perspectivas cognitivas han tenido influencia en la narratología reciente y en la manera como esta concibe sus categorías de estudio. Por ejemplo, Herman (2002; 2009), en concordancia con la noción de modelo mental (van Dijk \& Kintsch 1983), desarrolla la noción de storyworld o mundos narrativos para explicar cómo los receptores utilizan las inferencias activadas por indicios textuales para construir representaciones sobre la situación circunstante y el mundo evocado (Herman 2009, p. 209). Los mundos narrativos son, pues, modelos mentales activados por el discurso que enmarcan la situación y los eventos, es decir, la construcción del quién, qué, con quién, cuándo, dónde, por qué (Herman 2009, p. 106). Herman reconoce también la importancia de los guiones mentales y la experiencia organizada en ellos para la comprensión o co-construcción de las narrativas (2002, p. 98). Además, basándose en la teoría de prototipos de Rosch (1978), abre los límites de la categoría de narrativa y sostiene que la narratividad es una cuestión de grado (Herman 2002, p. 91).

Otra representante de la nueva narratología de corte cognitivo es Monika Fludernik (1996, 2003), quien propone una "narratología natural" con la que hace énfasis en el componente experiencial y deja atrás la noción tradicional 
aristotélica de narrativa entendida como secuencia de acciones conectadas por relaciones de causa efecto. Fludernik acepta que, para construir significado, los receptores tanto de textos como de cualquier evento de la vida cotidiana deben crear esquemas cognitivos de esa experiencia. A diferencia de otros modelos teóricos, el modelo de Fludernik propone que la característica esencial de la narrativa, esto es, la narratividad, es constituida por la experiencialidad: para la autora la narratividad está definida en términos de la experiencia humana, es decir, en términos cognitivos o parámetros 'naturales' basados en la experiencia de la vida real (1996, pp. 12-13). En un artículo posterior, la autora lo expone de la siguiente manera (2003, p. 245):

By introducing the concept of experientiality, I was concerned to characterize the purpose and function of the storytelling as a process that captures the narrator's past experience, reproduces it in vivid manner, and then evaluates and resolves it in terms of the protagonist's reactions and of the narrator's often explicit linking of the meaning of this experience with the current discourse context.

Así, Fludernik propone una redefinición del concepto de narratividad en el que la experiencia toma un lugar principal. En este sentido, la autora afirma que "there can therefore be narratives without plot, but there cannot be any narratives without a human (anthropomorphic) experiencer of some sort at some narrative level”' (1996, p. 13).

A pesar de que la tradición de considerar la narrativa como un tipo de texto se ha enfocado en revelar las unidades mínimas que la componen y en entender los procesos cognitivos que permiten su entendimiento y producción, como se puede observar de lo arriba expuesto, algunos de estos enfoques, sobre todo los más recientes, han considerado los elementos contextuales como parte del acto narrativo.

\subsection{El giro narrativo en las ciencias sociales}

La idea de que la narrativa no es simplemente un género textual, sino que es un modo de conocimiento y pensamiento, es decir, una forma esencialmente humana de aprehender la realidad, así como la concepción de las historias como concreción de la experiencia humana, fueron algunas de las ideas que dieron impulso al giro narrativo dentro de las ciencias sociales que tuvo auge en los años ochenta.

Riessman (2008, p. 14) localiza la gestación del giro narrativo en los años sesenta y la atribuye a cuatro movimientos: las críticas en la ciencias sociales de los métodos positivistas de investigación y su epistemología realista; el 
"memoir boom" en literatura y en la cultura popular; los nuevos movimientos identitarios, esto es, los esfuerzos de emancipación por parte de grupos minoritarios como gente de color, mujeres, gays, etc.; y el creciente interés por la exploración de vidas personales en contextos terapéuticos. Sin embargo, usando la metáfora de la autora (2008, p. 14), el estudio de narrativas, germinado en los sesenta, floreció en los años ochenta al incrementarse, de manera significativa, el interés por las narrativas en todos los campos de las ciencias sociales.

A raíz de este movimiento, las narrativas fueron consideradas como una potente herramienta para elicitar el conocimiento y la percepción que los individuos tienen con respecto a ciertos fenómenos sociales. El giro narrativo, empero, no fue una corriente homogénea en la que las distintas disciplinas compartieran las mismas líneas de pensamiento. La gran diversidad de aproximaciones analíticas y metodológicas se debieron a una falta de acuerdo sobre la concepción de narrativa y de los parámetros para su estudio. Por ejemplo, De Fina y Georgakopoulou (2012, p. 19) mencionan la discordancia de concepción sobre si la narrativa era un método para recoger y analizar datos o una epistemología. Hyvärinen (2006), por su parte, explica que mientras algunos autores defendían la narrativa como metáfora de vida, es decir, como una interpretación de la realidad (Bruner 1986) a partir de la cual concebimos nuestra existencia y construimos nuestra identidad (MacIntyre 1984; McAdams 1988), otros rechazaban esta comparación aseverando que la vida, a diferencia de las narrativas, no tiene principios ni medios ni finales (Mink 1987; White 1981). Otros investigadores, defensores del carácter epistemológico de la narrativa, se dedicaron a demostrar que la narratividad y la estructura narrativa surgían de la experiencia y de las acciones humanas (Carr 1986, Fludernik 1996). Otros señalaban que organizamos estas experiencias principalmente en forma de narrativa (Bruner 1991), la cual es una forma privilegiada de crear sentido (Ochs \& Capps 2001). Y se sostuvo que el hombre es, por naturaleza, "contador de historias" o, tal y como lo expresó el psicólogo MacIntyre (1984, p. 216), “a story-telling animal”.

Así pues, el giro narrativo creó un vasto campo interdisciplinario de teorías e investigaciones y, al cuestionar los métodos positivistas y cuantificadores de las ciencias sociales, provocó una reivindicación de los métodos cualitativos. Sin embargo, este movimiento ha sido blanco de críticas (cfr. Strawson 2004). Ha sido cuestionada la idea de que cada uno de nosotros experimentamos nuestra vida como y en la forma de una narrativa. Otra de las ideas criticadas ha sido la tendencia a concebir la narrativa como modalidad privilegiada de comunicación, asumiendo que lo que los hablantes cuentan es fiel reflejo de la realidad. Esta tendencia ha hecho pasar por alto el aquí y el ahora de la narración, es decir, el contexto en el que se desarrolla la historia y que inevitablemente la determina (De Fina \& Georgakopoulou 2012, p. 22). Otra crítica más ha sido la 
vaguedad que ha presentado la definición de narrativa, la cual, según Hyvärinen (2006, p. 21), ha sido raramente discutida por los teóricos del giro narrativo en contraste con los sociolingüistas y narratólogos que le han dedicado mucha más atención. Esta falta de especificidad, dicen De Fina y Georgakopoulou (2012, p. 22), "has hampered the development of agreed tools and frameworks of analysis”.

\subsection{La legitimación y sisematización de las narrativas en el ámbito de la lingüística}

El giro narrativo dentro de las ciencias sociales propició la proliferación de teorías, investigaciones y grandes avances sobre el análisis de narrativas en diferentes áreas. Dentro de la sociolingüística se desarrollaron distintos enfoques multi e interdisciplinarios que dieron gran importancia a la narrativa natural, es decir, a las narrativas orales de acontecimientos cotidianos.

El trabajo considerado como el pionero en este ámbito fue el llevado a cabo por William Labov (1972) -inicialmente desarrollado junto con Joshua Waletzky (Labov \& Waletzky 1967) - , el cual ha tenido particular influencia dentro de la lingüística.

Las narrativas de experiencias personales representaron para Labov, desde el punto de vista metodológico, una técnica efectiva para superar las dificultades que representaba la entrevista cara a cara. La pregunta prototípica a la que recurrió fue la concerniente al peligro de muerte: "Were you ever in a situation where you were in serious danger of being killed, where you said to yourself This is it?" (Labov 1972, p. 354). De acuerdo con Labov, el recuerdo y las emociones que provocaba dicha experiencia en los entrevistados hacían que se redujera la atención puesta en su producción lingüística (Labov 1972, p. 355) y se olvidaran de la formalidad de la situación involucrándose en la conversación con el entrevistador.

El modelo analítico, realizado conjuntamente con Joshua Waletzky (1967), tiene un carácter formal, ya que buscaba definir las unidades de la narrativa. En esta propuesta, la narrativa es definida como "[. . . ] one verbal technique for recapitulating experience, in particular, a technique of constructing narrative units which match the temporal sequence of that experience” (1967, p. 13). En este sentido, para que un texto sea considerado narrativa, el orden de los hechos narrados debe coincidir con el orden de los eventos (1967, p. 21).

Labov y Waletzky establecieron que las narrativas de experiencias personales bien formadas estaban estructuradas por seis secciones que cumplían funciones diferentes. Dichos componentes son: 1) el resumen que tiene la función 
de sintetizar la historia (respondería a la pregunta "what was this about?" Labov 1972, p. 370). 2) La orientación es un cuadro detallado de la situación en la que ocurren los eventos narrados (¿quién? ¿cuándo? ¿qué? ¿dónde? (1972, p. 370). 3) La complicación de la acción son los eventos sobre los que gira la narrativa (responde a la pregunta “then what happened?” (1972, p. 370). 4) La evaluación es una parte de la narrativa que expresa la actitud del narrador, su punto de vista sobre los hechos y personajes de su historia. A través de este componente, el narrador transmite al oyente el propósito de la narrativa, la razón por la que fue contada, lo que quería decir con ella, es decir, mediante la evaluación el narrador guía a su audiencia para que pueda interpretar la historia en los términos que él desea. Existen dos tipos de evaluación (Labov 1972): evaluación externa, donde el narrador detiene la acción para comentar directamente al oyente la actitud que tiene hacia su historia. Y la evaluación interna, enclavada en la historia y expresada mediante rcursos lingüísticos como intensificadores, superlativos, formas progresivas, dobles apositivos, etc. Labov (1972, p. 366) considera la evaluación como el elemento más importante, ya que una historia sin evaluación es solo una secuencia de eventos que harían que el oyente se preguntara sobre el sentido y razón de ser de la narrativa. 5) La resolución es la parte en la que se resuelve la complicación (“what finally happened?” (1972, p. 370). 6) La coda corresponde la parte colocada al final de la narrativa que indica que esta ha terminado. Según la teoría laboviana, las narrativas bien formadas tienen esta estructura, sin embargo, solo la complicación es esencial para reconocer un texto como narrativa.

Labov y Waletzky propusieron un modelo analítico que ha sido fuente de inspiración para el estudio de las narrativas en distintos ámbitos. Con su propuesta legitimaron las narrativas orales de experiencias personales como punto de partida para entender narrativas más complejas. En efecto, según afirma Edwards (1997, p. 139), la mayor contribución de Labov y Waletzky fue "the demonstration that everyday spoken narratives, especially those of "unsophisticated speakers", could be systematically studied without resort to the types and schemas already developed for literary works". Sin embargo, a pesar de la novedad que el modelo representó, ha sido criticado y se han evidenciado los problemas que implica (cfr. Edwards 1997; Schegloff 1997; Goodwin 1997; Ochs \& Capps 2001). Algunas de las críticas más extendidas (cfr. De Fina 2013a, p. 156) han sido que el modelo no es fácilmente aplicable a narrativas que no cumplan con los parámetros de la narrativa canónica larga e ininterrumpida. Asimismo, al tratar las narrativas como artefactos monológicos, el modelo se concentra en el narrador, desatendiendo el rol de la audiencia en la construcción de la actividad narrativa. Otro de los problemas es la ambigüedad de sus categorías de análisis, esto es, algunas de las clausulas, especialmente las que componen la evaluación, pue- 
den ser multifuncionales, lo cual dificulta su categorización. También se ha criticado la falta de atención tanto al contexto situacional como sociocultural (Schegloff 1997; Goodwin 1997; Edwards 1997; Ochs \& Capps 2001), así como la predilección por las narrativas aparecidas en entrevistas en detrimento de las surgidas en situaciones de conversación espontánea. Se le ha criticado también la atención puesta en un solo género narrativo, es decir, en las narrativas bien estructuradas. Esta delimitación deja fuera otros géneros como, por ejemplo, las narrativas hipotéticas (Riessman 1991), narrativas habituales (Riessman 1991; 1993, Ochs \& Capps 2001), pequeñas historias (small stories, Bamberg \& Georgakopoulou 2008), etc., aparecidos con frecuencia tanto en conversaciones espontáneas como en las mismas entrevistas. Finalmente, otra debilidad que se le ha adjudicado al modelo es la falta de consideración a las funciones sociales de la narrativa. Esto es, las narrativas se desarrollan y cumplen funciones específicas de acuerdo al contexto local, cultural, y conforme a los objetivos que los narradores se van fijando a lo largo del evento comunicativo. Este aspecto, ignorado por el modelo laboviano, ha sido una de las principales ideas que motivaron lo que De Fina y Georgakopoulou (2008) han denominado un "nuevo" giro en los estudios de la narrativa.

\subsection{Modelos lingüísticos para el estudio de las narrativas: del texto al contexto}

A raíz de las críticas al modelo analítico de Labov y del cuestionamiento a perspectivas provenientes del giro narrativo de las ciencias sociales que consideraban la narrativa como un modo privilegiado de construcción de la realidad y del “yo", desde finales de los años ochenta, comenzó a gestarse un importante cambio de óptica que ha desafiado las aproximaciones centradas en el texto y en su análisis estructural monológico. Los analistas han venido cada vez más a considerar las narrativas ya no como textos susceptibles de análisis puramente formal, sino como prácticas discursivas, socialmente modeladas, construidas colaborativa e interaccionalmente en contextos locales específicos. Así, a partir de este cambio de atención del texto al contexto han surgido diferentes modelos $\mathrm{y}$ enfoques que se han concentrado, por ejemplo, en el grado y las funciones que cumplen los interlocutores durante el proceso narrativo, la influencia que ejerce el contexto para el diseño de las historias, la manera como se relacionan con otras prácticas sociales y remiten a contextos más amplios, así como la variedad y complejidad de los formatos narrativos. 


\subsubsection{Más allá de la narrativa canónica}

Durante la conversación cotidiana se despliega una amplia gama de historias con formas diferentes que, muchas veces, no coinciden con la narrativa prototípica o canónica, caracterizada, de acuerdo con Ochs y Capps (2001, p. 57) como:

A coherent temporal progression of events that may be reordered for theoretical purposes and that is typically located in some past time and place.A plot line that encompasses a beginning, a middle, and end, conveys a particular perspective, and is designed for a particular audience who apprehend and shape its meaning.

Los estudios colocados dentro del nuevo giro narrativo han mostrado gran interés por las historias que se salen de este patrón, ya que la conversación cotidiana no solo alberga narrativas prototípicas que siguen una secuencia cronológica de acciones, sino que también presenta otro tipo de narrativas y otros tipos de discurso que se entremezcla. A este respecto, Ochs y Capps (2001, p. 18) afirman que:

Narrative is a cognitively and discursively complex genre that routinely contains some or all of the following discourse components: description, chronology, evaluation, and explanation [. . . ]. Settings, for example, are built from descriptions. Classic plots depict both a linear or more complex chronology of unfolding events and an overarching explanation of why a particular event transpired at a particular point in the narrative sequence. And, from its inception, the narrative is imbued with a moral and aesthetic evaluation of actions, emotions, thoughts, and worldly conditions.

En este sentido, Ochs y Capps (2001, p. 18) sostienen que la narrativa no puede ser sometida a un modelo genérico que indique los rasgos que la distinguen de otras formas de discurso. Para las autoras, las narrativas presentan un conjunto de dimensiones que desplegarán en diferentes grados y de distintas maneras. Desde su Enfoque Dimensional a la Narrativa apuntan que estas comprenden cinco dimensiones: tellership (extensión y tipo de involucramiento de los interlocutores); tellability (características que hacen que una narrativa amerite ser contada, la notoriedad que tienen los eventos para el narrador); embeddedness (grado en que una narrativa se puede disociar de la conversación); linearity (manera en que está ordenada cronológica y causalmente); y moral stance (evaluaciones sobre lo que está bien y lo que está mal). Cada una de estas dimensiones proporciona una gama de posibilidades que pueden ir variando en el curso de la narrativa (2001, pp. 19-20).

Otro intento por hacer justicia a las narrativas no canónicas se encuentra en el modelo para el análisis narrativo de Michael Bamberg y Alexandra Georgakopoulou (cfr. Bamberg 2006; Georgakopoulou 2006, 2007, 2015; Bamberg \& Georgakopoulou 2008) enfocado en las pequeñas historias (small stories). 
El término recoge una amplia variedad de narrativas “atípicas” que se caracterizan por su corta longitud en comparación con las narrativas canónicas. Sin embargo, el objetivo de la investigación concentrada en pequeñas historias no ha sido el de marcar una dicotomía entre estas y las historias extensas (big stories), sino en reconocer el pluralismo y heterogeneidad de las historias, así como su coexistencia con otras en el mismo proceso narrativo (Georgakopoulou 2015, p. 256). El término surgió como una reivindicación de las narrativas que, por diferir del prototipo, habían sido marginadas, tratadas despectivamente como historias fragmentadas, difusas, $\mathrm{y}$, por lo tanto, heterogéneas y difíciles de tratar (2015, p. 255). Además, el término fue elegido no solo con base en el significado literal que hace referencia a la longitud de las narrativas, sino que metafóricamente ha sido seleccionado en oposición a la tradición de las "grandes narrativas”, ya que las pequeñas historias contemplan pequeños incidentes y eventos ordinarios. Este tipo de narrativas se caracterizan por tratar eventos recientes ("esta mañana”, "anoche”) o en desarrollo, que ocurrieron o están por ocurrir y surgen de la necesidad de comunicar y compartir ese hecho (Georgakopoulou 2006). Además, algunas pequeñas historias podrían ser consideradas por un oyente externo como carentes de tema; sin embargo, estas historias reflejan el involucramiento interaccional de los participantes (De Fina \& Georgakopoulou 2012, p. 117).

Georgakopoulou (2015; De Fina \& Georgakopoulou 2012) ha reconocido algunos géneros de pequeñas historias, entre los que principalmente se encuentran a) noticias de última hora (breaking news) que son historias muy recientes o que se desarrollan al momento. Tienden a propiciar nuevas narrativas a través de la actualización de los eventos en curso o mediante proyecciones al futuro próximo; b) proyecciones (projections), que frecuentemente son propiciadas por las noticias de última hora e implican las interacciones organizadas episódicamente que sucederán en el futuro cercano; y c) historias compartidas (shared stories), que son referencias a otras historias o eventos conocidos por los interlocutores.

Bajo la luz de lo anteriormente expuesto, la investigación sobre small stories ha tenido gran trascendencia en los estudios de narrativas, ya que ha puesto en el mapa un tipo de historias que no habían sido tomado en cuenta por no cumplir con los criterios de la narrativa canónica. Sin embargo, estas características “make visible the teller's inconsistencies, the troubled identities, the ambivalent relationships with big issues such as race, gender, ethnicity, etc.” (Georgakopoulou 2015, p. 264). Es por esto que el marco de análisis de las pequeñas historias ha sido la base para estudios sobre identidad en narrativas (cfr. Georgakopoulou 2006; Bamberg \& Georgakopoulou 2008). 


\subsubsection{La narrativa como práctica}

Como hemos mencionado, la atención versada sobre el contexto en que surgen las narrativas ha sido una de las perspectivas que caracterizaron el nuevo giro narrativo. Los analistas conversacionales (cfr. Goodwin 1984; Jefferson 1978; Sacks 1974), por ejemplo, han enfatizado la necesidad de considerar el nivel local de interacción, es decir, estudiar las dinámicas conversacionales en el aquí y el ahora del evento comunicativo, poniendo especial énfasis en los puntos inicial y final de la conversación. Sin embargo, De Fina y Georgakopoulou (2008; 2015) van más allá de este nivel local sosteniendo que las narrativas surgen y se desarrollan no solo a partir de un nivel micro, sino que están condicionadas y remiten a procesos sociales y culturales más amplios. En este sentido, las autoras (2015, p. 3) proponen un enfoque sociointeraccional (Social Interactional Approach), el cual:

[. . .] looks for links and articulations between different levels of contexts and different scales in order to explain how the telling of stories shapes and is shaped by ideologies, social relations, and social agendas in different communities, times, and spaces.

El enfoque sociointeraccional atiende tanto al nivel micro como al nivel macro de la narrativa: se centra en las maneras en que los narradores y los interlocutores participan y construyen la historia y le dan sentido a partir del aquí y el ahora de la interacción; pero, además, propone hipótesis sobre cómo las prácticas discursivas, entre ellas la narrativa, se relacionan con otras prácticas dentro de una comunidad y cómo estas remiten a contextos más amplios hacia los cuales los participantes no están orientados inmediatamente (2013, p. 154).

De acuerdo con De Fina y Georgakopoulou (2008, p. 384), la perspectiva de la narrativa como práctica implica el reconocimiento de que esta se interconecta con otras prácticas, $\mathrm{y}$, por lo tanto, puede ser transportada en tiempo y espacio, (re)producida y modificada por los discursos que las contienen, así como establecer conexiones intertextuales con otras narrativas y otros géneros. Además, esta visión remite a la noción de comunidad de práctica, ya que los individuos forman grupos sociales en los que participan de manera activa, comparten una lengua, intereses, conocimientos, experiencias, e interactúan fortaleciendo con ello sus relaciones (Wenger et al. 2002). Las narrativas, pues, forman parte de las comunidades de práctica, por lo que "narratives can be expected to act as other shared resources, be they discourses or activities. In particular, they often form an integral part of a community's shared culture [. . .]” (De Fina \& Georgakopoulou 2008, p. 384). En este sentido, las narrativas pueden ser adaptadas estratégicamente para expresar identidad grupal o reafirmar y legitimar aspectos que componen dicha identidad, como los roles y objetivos colectivos. 
La pluralidad de las narrativas es tomada en cuenta por el enfoque sociointeraccional, cuyas autoras sostienen que no es posible definir la narrativa de manera cerrada a partir de características predefinidas (2008). Por tal razón, el enfoque atiende también narrativas no canónicas como las small stories y ha sido muy proficuo para tratar temas como el de la identidad (De Fina 2013a; 2015).

Finalmente, otra de las características del enfoque ha sido el de enfatizar la reflexión en los procesos de recolección de datos (2008, p. 385). Por ejemplo, la transcripción y la traducción de datos se han tratado con mucha atención, considerándolos no como procesos transparentes, sino como una elección que conlleva fuertes implicaciones para el análisis. Además, se considera errónea la dicotomía narrativas naturales contra elicitadas, ya que para este enfoque cualquier contexto situacional (setting) en el que se producen las narrativas se configura a partir de las interacciones de los participantes, sus relaciones, sus conocimientos compartidos, etc. A pesar de que el enfoque no favorece ningún método para la obtención de datos, de acuerdo con las autoras (2008, p. 385) los métodos etnográficos han dado buenos resultados, ya que permiten el estudio de las narrativas mediante la observación de la interacción de personas dentro de contextos cotidianos (De Fina 2013a).

\subsubsection{La entrevista: contexto interaccional para la elicitación de narrativas}

La entrevista como método para la recolección de datos ha sido muy reconocida en las ciencias sociales desde las primeras décadas del siglo XX (De Fina \& Perrino 2011, p. 1). Ha asumido un rol esencial como herramienta para las investigaciones cualitativas en los estudios de diversos campos como la educación, la antropología, la sociolingüística, la etnografía, la antropología lingüística, etc. Asimismo, la entrevista tuvo gran acogida entre muchos investigadores propulsores del giro narrativo, quienes sostenían que las historias de vida son imprescindibles para entender fenómenos sociales. La entrevista, pues, se volvió un método muy popular para elicitar este tipo de narrativas. Sin embargo, estas investigaciones se concentraron en el análisis de los contenidos y prestaron mínima atención a los contextos en los que se desarrollaron las entrevistas (De Fina \& Perrino 2011, p. 2), lo cual ha sido blanco de fuertes críticas. Se ha puesto en tela de juicio, por ejemplo, la tendencia a tratar de eliminar la participación del entrevistador obteniendo así una narrativa monológica. Se ha cuestionado también la afirmación de que es posible hacer que los entrevistados se olviden del evento, de tal manera que los entrevistadores pueden acceder a su comportamiento natural. Tal escepticismo ha derivado en la concepción de que la entrevista representa un contexto inauténtico y artificial para la recolección de datos. 
Dentro de los enfoques que han criticado abiertamente la entrevista como método de recolección de datos se encuentra el análisis conversacional. Dicho enfoque considera la entrevista como contexto que produce datos artificiales debido a que los investigadores manipulan o interfieren de algún modo en el comportamiento natural de los entrevistados (cfr. Heritage \& Atkinson 1984, p. 2). Sin embargo, esta postura ha sido matizada e incluso contestada por otras investigaciones que han enfatizado el carácter interaccional de la entrevista y la han reivindicado como un evento real de comunicación desarrollada y determinada por el contexto.

En las ciencias sociales, por ejemplo, la entrevista se ha concebido desde dos enfoques: uno realista o naturalista que se concentra en el contenido de las entrevistas (en el ¿qué?) y un acercamiento constructivista que se interesa por el modo en que actividades sociales como la entrevista son construidas y organizadas local y colaborativamente (Elliott 2005, pp. 18-19). Por lo que se refiere al ámbito de la lingüística, la consideración de la entrevista como un evento colaborativo ha tenido también resonancia. Por ejemplo, Briggs (1986) ha demostrado que, en contexto de entrevista, el principio positivista de neutralidad y no interferencia del investigador es solo una ilusión, ya que este tiene siempre injerencia en el desarrollo de tal actividad.

Otra de las nociones que han sido desafiadas por la investigación sociolingüística más recientemente ha sido la llamada paradoja del observador, término acuñado por Labov (1972) que se refiere a las dificultades para obtener un discurso natural en situaciones de investigación debido a la presencia del investigador. Labov sostenía que cuando los individuos cuentan historias personales, prestan menos atención al contexto de entrevista; asimismo, presuponía que, con una mínima intervención del investigador, la entrevista podría volverse muy similar a una conversación natural. En contraste con esta postura monológica y antintervencionista de la entrevista, otros trabajos dentro del campo de la sociolingüística desafiaron tales suposiciones a través del estudio de los efectos que la identidad de los interlocutores tenía en el estilo de la conversación. Así por ejemplo, los partidarios de la teoría de la acomodación (Bell 1984; Giles, Coupland \& Coupland 1991) argumentaron que los hablantes podían cambiar radicalmente su acento $\mathrm{u}$ otros aspectos prosódicos, sintácticos y discursivos de acuerdo a la identidad de sus interlocutores. Así pues, esta teoría ha contribuido a la consideración de la entrevista como un evento interaccional y no monológico, ya que el entrevistador es partícipe de la construcción de esta, dado que su identidad (individual, social, étnica, etc.) determina de algún modo la producción lingüística del entrevistado.

Con relación al estudio de narrativas producidas en contexto de entrevista, uno de los trabajos clásicos ha sido el volumen del psicólogo Elliot Mishler, 
Research interviewing: context and narrative (1986), donde expone el potencial de la entrevista para el entendimiento teórico de la acción y la experiencia humana (1986, p. vii) y la plantea como un evento conjuntamente construido entre entrevistado y entrevistador. En esta obra Mishler propone una nueva perspectiva de la entrevista en contraste con los enfoques estándares que, en primer lugar, han obscurecido la esencia de la entrevista, la cual es "an occasion of two persons speaking to each other” (1986, p. vii); en segundo lugar, han suprimido la noción de discurso reduciendo las preguntas y respuestas a estímulos/respuestas; en tercer lugar, han estandarizado las preguntas con el fin de que los informantes reciban el mismo estímulo; y finalmente, han ignorado el contexto personal y social de los entrevistados, tanto dentro de la entrevista como en el proceso de interpretación de los datos (1986, p. viii). Por tal motivo, Mishler (1986, p. ix) propone un enfoque que toma como base los siguientes principios:

(1) interviews are speech events; (2) the discourse of interviews is constructed jointly by interviewers and respondents; (3) analysis and interpretation are based on a theory of discourse and meaning; (4) the meanings of questions and answers are contextually grounded.

A pesar de que este trabajo ha sido paradigmático, desde su publicación no ha habido grandes avances con respecto al análisis de narrativas en contextos de entrevista (De Fina \& Perrino 2011, p. 6). Esto se ha debido, en parte, a la actitud de considerar la entrevista como un ámbito artificial para la elicitación de narrativas debido a la poca atención que los investigadores han puesto al contexto (De Fina 2009, p. 235). Lo anterior no significa que el interés hacia la entrevista considerada como un evento co-construido y modelado por el contexto se haya perdido por completo. Aun cuando estos estudios siguen siendo muy limitados en comparación con los estudios de la narrativa que ocurre naturalmente, en los últimos veinte años varios autores han hablado de la entrevista como un contexto interaccional donde surge la narrativa (Riessman 1991; 2008), del papel de los entrevistadores como co-constructores de relatos de experiencia personal (Bell 2006, Wortham 2001, Johnson 2008), o de la interacción entre entrevistador y entrevistado (Baker \& Johnson 2000). Esta reivindicación de la entrevista como evento propicio para el análisis narrativo se puede observar en estudios aún más recientes como el trabajo de De Fina (2009), quien sostiene que las entrevistas son eventos interaccionales y no encuentros sociales artificiales. En efecto, afirma que el hecho de que la narrativa sea elicitada no significa que las historias producidas sean artificiales y sean relatadas sin un objetivo social real, sino que simplemente los roles interaccionales y las relaciones sociales implicadas 
son diferentes de aquellas que surgen en una conversación ordinaria (2009, p. 237). ${ }^{1}$

\subsection{Narrativas e identidad}

La conexión entre narrativa e identidad ha sido conceptualizada bajo diferentes paradigmas dentro del ámbito psicológico, sociolingüístico, analíticoconversacional, por citar algunos. En este apartado expondremos algunas de las perspectivas que subrayan la naturaleza social de la identidad y la consideran como un proceso que se construye en la interacción, a través del habla y que se despliega con fines específicos asociados a la situación local. Pero, además, dedicaremos especial interés a propuestas que van más allá del nivel local de interacción y asumen que existe una conexión entre el nivel micro y el nivel macro del proceso identitario. Tales propuestas parten de la idea de que la construcción local de la identidad apunta hacia procesos sociales más amplios como las ideologías. A este respecto trataremos algunas teorías clave utilizadas en el estudio y explicación de los procesos identitarios, como la indexicalización y el posicionamiento.

\subsubsection{Identidad en interacción}

Como hemos apuntado anteriormente, dentro del giro narrativo hubo una fuerte tendencia a considerar que la narrativa era un medio para organizar nuestra experiencia, entender y dar sentido a nuestras vidas (Bruner 1990; 1991). En efecto, la narrativa se entendió como un espacio de configuración del "yo", ya que,

\footnotetext{
1 Por citar otro ejemplo, el tomo especial de Language and Society aparecido en 2011 con el título Narratives in interviews, Interviews in narrative studies recoge trabajos que demuestran la necesidad de reconocer la entrevista como un legítimo encuentro interaccional. La novedad de dicho volumen radica en que los autores no solo sostienen y demuestran que las narrativas son interactivamente complejas, sino que van más allá: reflexionan sobre la manera en que surgen y se negocian las relaciones entre entrevistadores y entrevistados (De Fina 2011); muestran cómo el evento interaccional emergente que representa la entrevista determina tanto las narrativas como el posicionamiento de los entrevistados (Wortham et al. 2011); reflexionan sobre algunos de los aspectos de la entrevista que han sido considerados problemas metodológicos que sesgan la investigación, como la paradoja del investigador (De Fina 2011); estudian los distintos niveles que implica la interacción (Koven 2011), y demuestran que las narrativas surgidas en entrevistas pueden ser tan interactivamente complejas y susceptibles de análisis como las narrativas que emergen en la conversación espontánea (Koven 2011).
} 
según esta perspectiva, nuestra identidad es construida mediante las historias que nos contamos a nosotros mismos y a otras personas sobre nuestra vida. A este respecto, McAdams (1988, pp. 17-18) afirmaba que “[i]t is an individual's story which has the power to tie together past, present, and future in his or her life. It is story which is able to provide unity and purpose [. . .]. The story is the answer to the question 'Who am I?' and 'How do I fit into an adult world?' Identity is a life story”. Para los estudiosos que sostienen esta perspectiva, las narrativas -o, más específicamente, las historias de vida- representan el recurso que permite el desarrollo coherente y positivo del "yo". Como expusimos en apartados precedentes, estos enfoques de tipo biográfico han sido contrastados por otra clase de aproximaciones que han considerado la narrativa como un evento interaccional. El estudio y teorización de la identidad ha sido también centro de interés de estos enfoques, los cuales parten de premisas y preguntas de investigación que difieren completamente de las planteadas por los enfoques biográficos:

For interactionists the issues of interest are not whether narrative contributes to a positive self-construction (for a critique of this principle see Strawson 2004), or whether subjects do in fact achieve coherent self-presentations. What they focus on is the process of identity construction itself - the strategies used by narrators, co-narrators, and their audience to achieve, contest, or reaffirm specific identities (De Fina 2015, p. 352).

Además, a diferencia de los enfoques que se orientan biográficamente hacia la identidad, los interaccionistas se concentran en los aspectos sociales de esta en detrimento de los mentales, ya que consideran que la construcción y el despliegue identitarios se desarrollan en contextos comunicativos. ${ }^{2}$

Evidentemente, la divergencia de visiones influye en el método de recolección de datos: mientras que los enfoques biográficos se enfocan casi exclusivamente en historias de vida, elicitadas mediante entrevistas diseñadas

2 Sin embargo, según la perspectiva con la que abordamos esta investigación, si bien es necesario reconocer la importancia de la interacción local para el despliegue y la construcción identitaria, no es posible rechazar automáticamente la existencia de mecanismos cognitivos que posibilitan la categorización social y la negociación de identidades dentro de la interacción. En este sentido, coincidimos con De Fina (2006, p. 355) cuando advierte que para el estudio de la categorización y la identidad es necesario evitar dos suposiciones:

"one is that the meaning of categories is exclusively managed at a local level and is in some sense "manifest" only within the interaction at hand; the other is that speakers hold in their minds a certain number of well-defined categories with associated meanings and that all they do in specific interactions is apply them. Analysts need instead to be able to link local identities to shared ideologies and beliefs, but they also need to account for the fact that the construction and presentation of identity is a process in constant development and that of its crucial sites of negotiation is interaction". 
para obtener narrativas coherentes y unificadas, los enfoques interaccionales analizan la construcción de identidades en narrativas diversas recabadas a través de la observación local de eventos comunicativos (incluida la entrevista).

\subsubsection{Más allá de la construcción identitaria a nivel local}

Estudios recientes sobre la categorización social en narrativas han apuntado la necesidad de reconocer que las identidades son construidas localmente, pero que estas están relacionadas con amplios constructos sociales como las ideologías o los discursos hegemónicos, los cuales tienen influencia en la interacción local y en el despliegue identitario (Bucholtz 1999; $c f r$. volumen editado por De Fina, Schiffrin \& Bamberg 2006). En esta línea, constructos teóricos como los de posicionamiento e indexicalización han permitido demostrar la conexión entre el nivel micro de interacción y el nivel macro en el que operan distintos procesos sociales como expondremos a continuación.

\subsubsection{Indexicalización}

Si bien el trabajo de categorización de identidades surge en y de la interacción, gran parte de este trabajo se realiza de manera indirecta mediante procesos simbólicos. Es decir, los individuos suelen relacionar ciertos constructos lingüísticos como sonidos, palabras, estilos, expresiones, etc., con determinados grupos o categorías sociales, y hacen uso de estos recursos para conceptualizar y construir la identidad tanto de dichos grupos como de sí mismos. Este proceso de asociación entre unidades lingüísticas y determinados elementos del entorno social se conoce como indexicalización (indexicality). El término fue propuesto por Silverstein (1976), quien, partiendo de la idea de que los signos (lingüísticos y no lingüísticos) cumplen gran variedad de funciones, plantea un modelo pragmático para el análisis del comportamiento lingüístico, que, en palabras del autor "allows us to describe the real linkage of language to culture and perhaps the most important aspect of the 'meaning' of speech" (1976, p. 12). El concepto de indexicalización, pues, se basa en la idea de que los símbolos indican o apuntan hacia entidades externas a ellos (Silverstein 1979, p. 206):

[. . .] language is "functional," inasmuch as by characteristic distribution of particular forms in certain contexts of use, these forms (or, rather, tokens of them) serve as specifically linguistic indicators (or indices) differentially pointing to (indexing) configurations of contextual features.

Dentro de los estudios sobre identidad en narrativas se le ha otorgado gran atención al concepto de indexicalización, ya que el narrador remite a (indexa) 
ciertas categorías sociales a través de la utilización de determinados acentos, palabras, estilos, etc. durante la narración. Al hacer esto, el individuo propone no solo la identidad de tales grupos, sino que despliega su propia identidad y su actitud hacia ellos mostrando empatía o distanciamiento. Debido a lo anterior, investigaciones recientes sobre identidad en narrativas han dedicado especial atención a la manera en que se utilizan distintos recursos indexicales para la construcción de categorías sociales como la etnicidad ( $c f r$. Bucholtz 1999, 2009) o el género (cfr. Ochs 1992; Bucholtz 1999, 2009; Kiesling 2006).

Ochs (1992) sostiene que los hablantes utilizan ciertas formas lingüísticas para alcanzar sus objetivos comunicativos dentro de la interacción y a través de estas se despliegan determinadas identidades. La autora extiende el concepto de indexicalización, sosteniendo que la conexión entre una cierta forma linguiística y una identidad social particular no siempre es directa. Es decir que las formas lingüísticas que indexan identidad son primeramente asociadas con actitudes y posturas (como fuerza, inseguridad, delicadeza, etc.), las cuales a su vez son asociadas a categorías sociales particulares (como el género). Bajo esta perspectiva, propone que la relación indexical entre lenguaje y significados sociales comprende dos niveles: indexicalización directa e indexicalización indirecta (1992, p. 343). A nivel directo, las formas lingüísticas se asocian con actitudes/posiciones que adopta el hablante frente a su interlocutor durante la conversación en curso. Un ejemplo de indexicalización directa lo podemos ver con el marcador discursivo de la variedad mexicana güey. Como lo demuestra Bucholz (2009), en las conversaciones entre jóvenes, este marcador indexa solidaridad y camaradería por parte del hablante frente a su interlocutor A nivel indirecto, estas mismas formas lingüísticas son asociadas a constructos sociales más amplios como los estilos o las identidades. En este sentido, siguiendo con el ejemplo de Bucholz (2009), en el contexto publicitario estadounidense el marcador güey indexa un estilo urbano de masculinidad heterosexual juvenil de clase media. Así las cosas, a nivel indirecto entra en juego la ideología ya que tales constructos y formas lingüísticas son relacionados con grupos sociales particulares. Bucholz (2005, p. 594) afirma que en la formación de identidad durante el evento comunicativo, la indexicalización depende en gran medida de estructuras ideológicas, ya que las asociaciones entre el lenguaje y la identidad se basan en creencias y valores culturales, es decir, en ideologías sobre tipos de hablantes que realizan determinadas producciones lingüísticas.

Las investigaciones sobre indexicalización se han enfocado principalmente en los recursos lingüísticos que proyectan identidades específicas. Kiesling (2006), sin embargo, propone que no solo los elementos lingüísticos pueden apuntar hacia entidades externas, sino que la narrativa por sí misma es capaz de realizar trabajo indexical, ya que puede remitir a Discursos con "D" mayúscula o discursos domi- 
nantes. Kiesling sostiene que el conocimiento cultural compartido (Discursos) de los interlocutores es la base para la correcta interpretación y justificación de las narrativas a nivel local. Asimismo, afirma que las narrativas son una práctica que fomenta la recreación de identidades hegemónicas y la circulación de Discursos, lo cual contribuye a su reforzamiento y al mantenimiento de su hegemonía (2006, p. 280).

\subsubsection{Teoría del posicionamiento}

La teoría del posicionamiento (positioning theory) ha sido una de las más relevantes para explicar el modo en el que los narradores construyen y negocian su(s) identidad(es) y las de sus personajes durante el evento narrativo. La noción de posicionamiento ha sido primeramente desarrollada dentro de las investigaciones sobre identidad y discurso y más recientemente ha sido aplicada a los estudios de narrativas. Deppermann (2015) explica que el concepto tiene sus orígenes en la noción de posición de sujeto (subject position) propuesta por Foucault (1969), ${ }^{3}$ quien se interesaba por la historia de las formaciones discursivas. Para Foucault, los discursos posicionan al individuo en términos de estatus y poder, legitiman el conocimiento y, por lo tanto, determinan la interpretación del yo, del mundo (social) y de los otros (Deppermann 2015, p. 371).

El concepto de posicionamiento fue introducido posteriormente por Bronwyn Davies y Rom Harré (1990) en un trabajo que tuvo mucha influencia en el campo de la investigación narrativa. En su artículo, los autores lo definieron como "the discursive process whereby selves are located in conversations as observably and intersubjectively coherent participants in jointly produced story lines" (1990, p. 48). Como muestra la cita, para Davies y Harré, el posicionamiento es un mecanismo discursivo mediante el cual se construye el "yo" llevado a cabo dentro de la interacción social a través de narrativas. De acuerdo con los autores, los hilos narrativos (story lines) son la principal estructura organizativa de los discursos que los individuos emplean para dar sentido a su experiencia pasada. Estos son parte constituyente de las prácticas discursivas, las cuales nos permiten aprender y dar sentido a categorías sociales, desarrollar nuestro propio ser e interpretar el mundo (1990, p. 47). En efecto, los autores sostienen que el desarrollo y adquisición de la identidad, así como la interpretación del mundo, se realizan mediante diferentes procesos: 1) el aprendizaje de categorías, lo cual implica incluir y excluir individuos de estas; 2) la participación en prácticas discursivas, ya que es allí donde se asignan e internalizan las categorías

3 Foucault, M. (1969). L’Archéologie du savoir. Paris: Gallimard. En: Deppermann, Arnulf (2015): "Positioning”, in: A. De Fina \& A. Georgakopolou (eds.), The handbook of narrative analysis. Somerset, US: Wiley-Blackwell, p. 371. 
y los hilos narrativos a través de los cuales se elaboran diferentes posicionamientos; 3) el posicionamiento de sí mismos en términos de hilos narrativos y categorías, lo cual significa posicionarse dentro de una categoría en detrimento de otra; y 4) el reconocimiento de sí mismo como miembro de varias subclases de categorías dicotómicas (1990, p. 47). Este reconocimiento implica un compromiso emocional con la pertenencia a la categoría y el desarrollo de un sistema moral referente a dicha pertenencia.

Más recientemente, la teoría del posicionamiento ha tenido muy buena acogida y ha sido reelaborada dentro de la investigación narrativa de tipo interaccional. Tales aproximaciones enfatizan el hecho de que la identidad es multifacética, es decir, que los contextos discursivos determinan y hacen relevantes diferentes identidades. En este sentido, sugieren que el posicionamiento brinda evidencia de las múltiples facetas de la identidad, las cuales son activamente proyectadas y negociadas localmente. Asimismo, destacan el hecho de que las posturas que un hablante adopta pueden ser incluso contradictorias o ser revisadas y modificadas a lo largo de la interacción. Dentro de esta perspectiva se encuentran los trabajos realizados por Bamberg (1997), Bamberg y Georgakopoulou (2008), De Fina (2013b), Wortham (2001), Lucius-Hoene y Deppermann (2000), entre otros, cuyos estudios y propuestas teóricas han contribuido al enriquecimiento de la teoría del posicionamiento.

Dentro de las investigaciones de narrativas en interacción, Michael Bamberg (1997) amplía la noción de posicionamiento proponiendo un modelo que comprende tres niveles formulados mediante tres preguntas distintas:

Nivel 1: "How are the characters positioned in relation to one another within the reported events?” (1997, p. 337). El nivel 1 de posicionamiento implica la manera en la que los personajes se posicionan en relación con otro(s) personaje(s) frente a frente dentro del mundo de la narrativa (story world). En este sentido, el análisis narrativo a este nivel está enfocado en develar cómo son construidos los personajes dentro de la historia en términos, por ejemplo, de protagonista, antagonista, perpetrador, víctima, héroe, villano, etc.

Nivel 2: "How does the speaker position him- or herself to the audience?" (1997, p. 337). Este nivel opera en el plano interaccional, es decir, concierne a la posición que toma el narrador frente a su(s) interlocutor(es) en el espacio (el aquí y el ahora) en que se suscita la narración (story-telling world). Este nivel indica el "yo" que el narrador quiere mostrar a su audiencia. En otras palabras, a partir de diferentes recursos discursivos, el narrador indica cómo quiere ser visto; por ejemplo, se puede presentar ante su interlocutor como una persona inteligente, racional, madura, etc. (Bamberg 2004). 
Nivel 3: “How do narrators position themselves to themselves?” (1997, p. 337). El tercer nivel de posicionamiento indica la manera en la que el narrador se construye así mismo como un tipo de persona específico. En este nivel el narrador da respuesta a la pregunta “¿Quién soy?”. Para el investigador, este nivel representa un aspecto de la identidad que va más allá de la situación local de interacción.

Posteriormente, Bamberg (2004; cfr. también Bamberg \& Georgakopoulou 2008) reformula el nivel 3 puntualizando la dimensión extrasituacional de la identidad. Esto es, el tercer nivel se ocupa de la manera "how the speaker/narrator positions a sense of self/identity with regard to dominant discourses or master narratives” (Bamberg \& Georgakopoulou 2008, p. 385). En efecto, el nivel 3 devela cómo el narrador despliega parte de su identidad tomando determinada postura frente a discursos hegemónicos, culturales o a posiciones sociales normativas, ya sea adoptando tales discursos, mostrando neutralidad, distanciándose de ellos, criticándolos o resistiéndolos (Bamberg 2004, p. 249). En este nivel se analiza la manera en que el narrador vuelve relevantes esos discursos para la interacción y, a través de esto, cómo se construye a sí mismo como un tipo específico de persona (Bamberg y Georgakopoulou 2008, p. 391).

Otra contribución al desarrollo de la noción de posicionamiento se debe a Lucius-Hoene y Deppermann (2000, cfr. también Deppermann 2015), quienes hacen uso de esta herramienta para analizar entrevistas de narraciones autobiográficas. Basándose en el modelo por niveles de Bamberg, hacen una descripción más detallada de los recursos de posicionamiento utilizados en los niveles 1 y 2.

En el mundo de la narrativa (nivel 1), la posición que toman tanto el "yo" narrado como los personajes se distingue principalmente mediante los diálogos y las acciones reportados por el narrador. Tal reporte, sin embargo, es estratégicamente diseñado desde su punto de vista actual. El narrador no presta únicamente voz a sus personajes, sino que diseña activamente la historia a través de medios lingüísticos con los cuales los posiciona de acuerdo a cómo quiere que sea interpretada su historia. Estos recursos son (Deppermann 2015, pp. 378-379):

- La descripción y delimitación de categorías sociales;

- expresiones y maneras de hablar asociadas con grupos sociales y registros (indexicales evaluativos, ver infra Wortham 2001, p. 72);

- la elección de la granularidad de la representación, acciones y eventos reportados;

- nexos cohesivos que establecen causalidad, contraste, concesión e instrumentalidad;

- gestión de la información en los segmentos de orientación y de fondo.

A nivel interaccional (nivel 2), Deppermann (2015, p. 379) identifica cuatro tipos de posicionamiento: 


\section{1) Autoposicionamiento del narrador mediante actividades autorreflexivas $y$ metanarrativas}

Durante el evento narrativo, el narrador, desde su punto de vista actual, toma una postura explícita con respecto a eventos y a su "yo" del pasado a través de comentarios retrospectivos metanarrativos y evaluaciones. Este doble plano temporal (el mundo de la narrativa y el mundo de la narración) permite observar la naturaleza multifacética de la identidad que a veces, incluso, se muestra contradictoria no coincidiendo en ambos planos. En este nivel, además de que el narrador puede expresar un cambio de posicionamiento con respecto al "yo-personaje", también es posible que surja una reflexión sobre su "yo" actual y los acontecimientos que lo han moldeado.

\section{2) Posicionamiento interaccional mediante el diseño narrativo}

La manera cómo el narrador diseña su historia indica el modo como este se presenta a sí mismo ante su interlocutor. Su perspectiva subjetiva, sus posturas morales, emocionales y evaluativas, así como su afiliación o distanciamiento de ciertas categorías sociales, etc. son proyectadas por el diseño narrativo mediante recursos como el humor, la ironía, cambios de código, léxico, construcciones que indexan grupos sociales, etc. El posicionamiento del interlocutor (el entrevistador), además, determina el diseño narrativo y el posicionamiento que toma el narrador, quien puede proyectar la misma postura que su oyente o distanciarse de esta.

\section{3) Posicionamiento interaccional por medio de actividades meta-narrativas del narrador}

Entre las actividades metanarrativas que promueven la interacción se encuentran la formulación, por parte del narrador, de suposiciones o preguntas sobre el conocimiento del receptor (entrevistador) y su postura evaluativa. Por ejemplo, riendo, buscando acuerdo, extendiendo explicaciones, etc.

\section{4) Posicionamiento interaccional por parte del receptor de la historia}

Aunque el entrevistador no pueda intervenir de la misma manera como sucede en la conversación cotidiana, su desempeño e identidad contribuyen igualmente a dar forma al posicionamiento del narrador. Lucius-Hoene y Deppermann (2000, p. 213) identifican dos maneras mediante las cuales el entrevistador participa como coautor de la narrativa. Según señala Deppermann (2015, p. 379), el investigador debe actuar como un oyente discreto que no obstruya la comunicación y debe ejecutar actos comunicativos como mostrar atención, entendi- 
miento y aceptación mediante reacciones generalmente no verbales para hacer que la historia continúe. Estas reacciones son indicios que transmiten la postura del oyente hacia la historia y tienen gran impacto para las siguientes participaciones del narrador (Lucius- Hoene \& Deppermann 2000, p. 213). En segundo lugar, la coautoría del entrevistador es el resultado del posicionamiento que explícita o implícitamente el narrador le atribuye a lo largo de la entrevista. Estas actividades de posicionamiento dependen de las presuposiciones que el narrador tiene sobre las preferencias y objetivos del entrevistador - lo cual también determina la selección de temas, explicaciones, recursos retóricos, categorizaciones, etc.-. Aunado a esto, Lucius-Hoene y Deppermann (2000, p. 214) explican que ciertos aspectos del entrevistador (como la edad, el género, el rol de investigador, etc.) provocan que el narrador haga presuposiciones, cree expectativas y evaluaciones y posicione a su oyente de distintas maneras dentro de la entrevista (por ejemplo, como un experto, una mujer que sabe lo que significa el matrimonio, etc.). Tales posiciones no siempre son atribuidas explícitamente, sino que pueden ser asignadas mediante insinuaciones, argumentaciones, o mediante preguntas al entrevistador para incitar acuerdo, indignación, contrariedad, etc. De esta manera, el entrevistado puede inducir al entrevistador a que se posicione de tal manera que sostenga la identidad que él quiere mostrar localmente.

Para terminar este acápite haremos referencia al trabajo de Stanton Wortham (2000, 2001), quien, basándose en la sociolingüística interaccional y el análisis conversacional, propone nuevas pautas para el análisis del posicionamiento, muy útiles en el marco de esta investigación.

De acuerdo con Wortham, las narrativas autobiográficas, además de tener una función representacional, tienen una función interaccional; es decir, que el narrador, cuando habla de su biografía, más allá de describir un "yo” preexistente, refuerza y recrea cierta identidad frente a su audiencia y en ocasiones toma conciencia sobre quién fue y cómo es ahora. En sus estudios, Wortham se aboca a describir "how the self represented in an autobiographical narrative and the self enacted in the same narrative can interrelate so as partly to construct the self" (Wortham 2000, p. 4, cursivas del original). Aunque Wortham no hace referencia al modelo de Bamberg (1997), la cita anterior refleja una coincidencia con la construcción identitaria en los niveles 1 y 2, así como el interés por comprender la interrelación que existe entre estos.

Básandose en el concepto de indexicalidad de Silverstein (1976) y en el de voz $(\text { voice })^{4}$ de Bakhtin (1981), Wortham (2001, p. 63) explica que no es necesa-

4 Bakhtin (1981) sostiene que los enunciados pueden contener varias "voces"; por ejemplo, la voz del escritor (o del narrador), la voz de alguien al que se hace referencia, la voz de otro para 
rio que el narrador indique explícitamente su posición, sino que lo puede hacer mediante la yuxtaposición de voces de distintos personajes (citando, parafraseando o imitando). Esto es, utilizar cierta voz implica usar palabras que indexan ciertas posiciones sociales (Wortham 2001, p. 38) y esto indica, a su vez, la posición o actitud que el narrador toma hacia dicho grupo.

Wortham plantea, pues, la necesidad de identificar los elementos lingüísticos y paralingüísticos mediante los cuales el narrador se posiciona a sí mismo y a otros interaccionalmente. Propone cinco tipos de indicios (cues) que los narradores utilizan para indexar voces (Bakhtin 1981) y para posicionarse con respecto a ellas (Wortham 2001, pp. 70-75; también Wortham 2000, pp. 22-23):

\section{1) Referencia y predicación}

Se refiere a la manera cómo el narrador identifica socialmente a sus personajes, eventos, objetos, acciones. Esto es, los narradores eligen ciertos elementos lingüísticos para categorizar a sus personajes dentro de reconocibles tipos sociales y, de esta manera, se posicionan a sí mismos con respecto a estos. Algunas de estas herramientas lingüísticas son los nombres propios (Tomás), títulos (Mr. Johnson) o términos de parentesco (mi tío Tomás), los cuales ubican al narrador en una posición social específica frente a su personaje. Asimismo, los adjetivos son también elementos que permiten caracterizar a los participantes narrados y demuestran una posición evaluativa por parte del narrador.

\section{2) Descriptores metapragmáticos}

Son los llamados verba dicendi (verbs of saying) usados para categorizar acciones lingüísticas (p.ej. regañar, acusar, discutir, mentir, admitir, negar etc.). Tales verbos son metapragmáticos (Silverstein 1976) porque hacen referencia y caracterizan el discurso de alguien. Cuando el narrador elige usar uno de estos verbos y no otro, sugiere una evaluación moral de sus personajes.

\section{3) Citación}

Las citas que el narrador hace del discurso de los personajes también contribuyen a su caracterización o categorización dentro un cierto tipo social. Las citaciones son graduales: el narrador puede decidir reproducir las palabras de los participantes narrados de manera semi-directa, directa o indirecta. Sin embargo, en cualquier caso, el narrador filtra inevitablemente el discurso de sus

quien se transmite el mensaje, etc. Todas las voces pueden mezclarse a lo largo de la comunicación y convertirse en parte de los significados sociales indexados. 
personajes simplemente por el hecho de haber elegido determinada cita y adicionándoles cierta entonación.

\section{4) Indexicales evaluativos}

Se trata de descripciones, expresiones, maneras de hablar, acentos, etc., asociados con ciertos grupos sociales. El narrador puede caracterizar a sus personajes haciéndolos hablar o actuar de tal manera que estos indexen ciertos tipos de personas. Los indexicales evaluativos, dice Wortham (2001, p. 74), "not only indexes particular voices but also position the narrator with respect to these voices”.

\section{5) Modalización epistémica}

El último tipo de indicios de posicionamiento es la modalización epistémica, la cual se refiere a las elecciones lingüísticas relacionadas con el estado de conocimiento del narrador frente a sus personajes. Por ejemplo, el narrador puede expresar una visión omnipresente de la situación o referir acceso epistémico solo a ciertos personajes. Además, el estado epistémico del narrador durante el evento narrativo puede variar del estado epistémico de él mismo como personaje (Wortham 2000, p. 23). Los modalizadores epistémicos, pues, evidencian dos niveles de posicionamiento: el del mundo de la narrativa y el de la narración. En efecto, el narrador puede realizar saltos entre estos dos niveles mediante este tipo de elementos lingüísticos. Deppermann (2015, p. 376) cita como modalizadores epistémicos verbos de pensamiento (creer, pensar); adverbios (claro, posiblemente); y marcadores discursivos (¿sabes?).

Hasta ahora hemos dado una panorámica de los enfoques y modelos teóricos que han hecho de la investigación narrativa una disciplina teórica bien consolidada dentro de las ciencias sociales. Asimismo, a partir de los resultados que han arrojado varios estudios hemos confirmado que las narrativas son un campo muy proficuo para la exploración de la identidad y que la entrevista, además de ser una herramienta metodológica, es un contexto interaccional que permite obtener narrativas de manera espontánea. Finalmente, hemos expuesto los modelos y herramientas teóricos sobre los cuales nos basaremos para hacer el análisis de la parte empírica de este estudio. A continuación expondremos el enfoque con el cual abordamos esta investigación, así como las pautas metodológicas y el corpus objeto de nuestro análisis. 